\title{
Le point des connaissances sur Brevibacterium linens
}

\author{
par \\ P. BOYAVAL et M. J. DESMAZEAUD
}

\section{Note de la Rédaction}

Cet article constitue la première mise au point bibliographique que publie LE LAIT.

Sa présentation diffère donc de celle qui est de règle pour les mémoires (originaux).

La publication de telles mises au point sera maintenant régulière, au rythme de 2 à 3 par an.

Tous les domaines de la science et de la technologie laitière seront concernés.

\section{Sommaire}

I. Introduction $\ldots \begin{array}{llllllllllllllllll} & \ldots & \ldots & \ldots & \ldots & \ldots & \ldots & \ldots & \ldots & \ldots & \ldots & \ldots & \ldots & \ldots & \ldots & \ldots & \ldots & 189\end{array}$

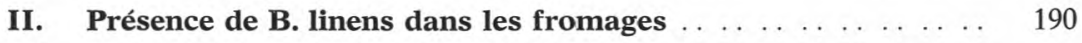

III. Position taxonomique de B. linens

III.1. Problèmes généraux de la classification des bactéries corynéformes et de B. linens . . . . . . . . . . . . . . . . . . . . . . . . . . . . . . . 193

III.2. Composition de la paroi de B. linens . . . . . . . . . . . . . . . . 194

III.3 Composition lipidique . . . . . . . . . . . . . . . . . . . . . . . . . . . . . . . . . . . 195

III.4. Aspects génétiques $\ldots \begin{array}{llllllllllllllll} & \ldots & \ldots & \ldots & \ldots & \ldots & \ldots & \ldots & \ldots & \ldots & \ldots & \ldots & \ldots & \ldots & & 195\end{array}$

III.5. La pigmentation de $B$. linens . . . . . . . . . . . . . . . . . . . . . . . . 197

III.6. Autres propriétés utilisables pour l'identification de B. linens 198

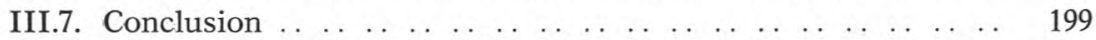

Laboratoire de Microbiologie Laitière et Génie Alimentaire, I.N.R.A., C.N.R.Z. 78350 Jouy-en-Josas (France). 


\section{Exigences nutritionnelles}

IV.1. Problème de l'isolement et du dénombrement . . . . . . . 199

IV.2. Utilisation de l'azote par B. linens et exigences vitaminiques 200

IV.3. Utilisation des sources carbonées . .

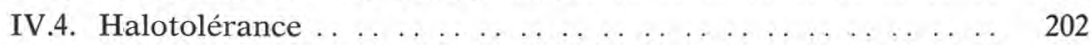

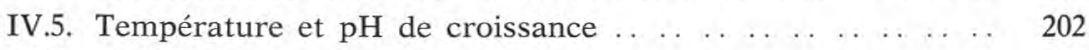

IV.6. Résistance aux antibiotiques . . . .

IV.7. Autres propriétés . . .

V. Activités protéolytiques de B. linens

V.1. Activité protéolytique endopeptidasique .. . . . . . . . . . . . . 203

V.2. Activités exopeptidasiques :
V.2.1. Exopeptidase extracellulaire
V. .

$\begin{array}{llllllllll}\text { V.2.2. Exopeptidases intracellulaires } & \ldots & \ldots & \ldots & \ldots & \ldots & \ldots & \ldots & \ldots & 205\end{array}$

VI. Activités lipolytique et estérasique de $\mathbf{B}$. linens $\ldots \ldots \ldots$. . . 205

VII. Production de substances volatiles. Dégradation des acides

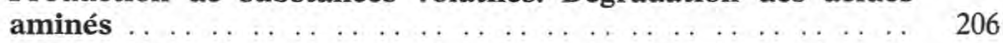

VIII. Rôle de B. linens au cours de l'affinage des fromages . . . 207

\section{Rés u mé}

Brevibacterium linens est un des agents de l'affinage de nombreux fromages. Ses activités protéolytiques s'exercent à la surface des pâtes où ses catabolites (produits soufrés, ammoniac, amines, composés aromatiques) contribuent à la flaveur finale des produits.

La composition de la paroi de $B$. linens est exceptionnelle : présence d'acides teichoïques particuliers, d'acide méso-diaminopimélique lié sans pont peptidique à la D-alanine voisine, absence de galactose et d'arabinose.

Ses lipides ne contiennent pas d'acide mycolique, caractéristique de nombreuses bactéries corynéformes. Ses pigments, de type caroténoïde aromatique, sont très peu fréquents chez les bactéries. Les faibles taux d'hybridation $A D N-A D N$ et $A D N-A R N$ ribosomique entre $B$. linens et les autres bactéries de type corynéforme incitent également à redéfinir l'espèce $B$. linens.

La plupart des souches de $B$. linens n'utilisent l'azote que sous forme organique. La présence d'acide pantothénique ou d'acide paraaminobenzoïque paraît indispensable à la croissance qui est optimale en présence de lactate ou d'acétate.

\section{Mots clés}

Brevibacterium linens - Fromages - Paramètres taxonomiques - Nutrition Activités protéolytiques. 


\section{Su m mary}

\section{CURRENT STATE OF RESEARCH ON BREVIBACTERIUM LINENS}

Coryneform bacteria have been encountered in a wide variety of habitats, ranging from soil and sea water to poultry litter and cheese. B. linens is often involved in cheese ripening. It is reported to tolerate a high $\mathrm{NaCl}$ concentration $(200 \mathrm{~g} / \mathrm{l})$. The fact that $\mathrm{B}$. linens is strictly aerobic enables it to exert its proteolytic activities mainly on the surface of the cheese in association with yeasts, molds and other bacteria. In addition to their contribution to the product's flavour, the catabolites of B. linens inhibit growth of many Grampositive and Gram-negative food poisoning bacteria as well as several yeasts and molds. The cell wall composition of $\mathrm{B}$. linens is uncommon: unusual teichoïc acids, meso-diamino-pimelic acid directly cross-linked, lack of galactose and arabinose. No mycolic acid, typical of numerous coryneform bacteria, is present in its lipids. Its pigments of aromatic carotenoïd type are unusual in bacteria. B. linens is able to produce methanethiol from L-methionine. These results and the low rates obtained for DNA-DNA and DNA-RNA hybridizations between B. linens and other coryneform bacteria, prompted bacteriologists to redefine the species B. linens.

It is difficult to find a selective culture medium for $\mathrm{B}$. linens because of its complex nutritional requirements. Most of strains of B. linens require organic nitrogen. Pantothenic acid or para-aminobenzoïc acid appears essential for its growth which is optimum with lactate or acetate as carbon source. This alkalophilic bacteria grows well at $25^{\circ} \mathrm{C}$ if the strain comes from a natural source other than animal. Extracellular proteolytic activities are very variable among the strains. An extracellular aminopeptidase has been extracted and purified from B. linens ATCC 9174. B. linens produces volatile fatty acids from carbohydrates and butter fat between $p H 5.0$ and 8.8. Its deamination activity is the source of a considerable production of ammoniac. The large population of bacteria related to $\mathrm{B}$. linens produces specific flavour components which play an important role in the formation of cheese aromas.

Key words:

Brevibacterium linens - Cheese ripening - Taxonomic parameters - Nutrition Proteolytic activities.

\section{INTRODUCTION}

Les bactéries corynéformes, auxquelles appartient Brevibacterium linens (Rogosa et Keddie in Bergey's manual, 1974), sont largement distribuées dans la nature. Elles sont présentes dans les océans 
(Wood, 1967 ; Bousfield, 1976), les sols (Crombach, 1974a), les litières de volailles (Mohan, 1981 ; Schefferle, 1966), les boues activées (Keddie et Cure, 1977), les produits laitiers (Abd-El-Malek et Gibson, 1952 ; Crombach, 1972 ; Jayne-Williams et Skerman, 1966), mais aussi sur les plantes (Keddie, Leask et Grainger, 1966; Owens et Keddie, 1969), les poissons (Crombach, 1974a), les abats de volailles, les œufs (Kraft et al, 1966), les pommes de terre (Grimmer cité par Thomasow, 1950), sur la peau humaine (Pitcher et Noble, 1978), ainsi que dans les eaux résiduaires provenant de porcheries (Seiler et Hennlich, 1983) et d'étables (Hrubant, 1973).

Les bactéries corynéformes pathogènes pour l'homme (Corynebacterium diphtheriae, C. ulcerans, C. haemolyticum) (Pilet et al, 1975), pour les animaux (Corynebacterium pseudotuberculosis, $C$. pyogenes, C. equi, $C$. bovis, $C$. murium), et pour les végétaux (Corynebacterium flaccumfaciens, $C$. poinsettiae) (Lelliot, 1966), par leurs manifestations cliniques et les dégâts occasionnés aux récoltes, ont attiré très tôt l'attention des bactériologistes. Les bactéries corynéformes commensales ne font réellement l'objet de recherches intensives que depuis les années 1960. Ces recherches sont le fruit d'intérêts économiques importants. Ces micro-organismes peuvent être de remarquables producteurs d'acides aminés : acide glutamique (Veldkamp, Berg et Zevenhuisen, 1963), lysine (certaines souches de Corynebacterium glutamicum peuvent produire jusqu'à $50 \mathrm{~g}$ de lysine par litre de milieu nutritif) (Phaff, 1981). Le rendement de certains mutants de Brevibacterium lactofermentum est déjà de $30 \mathrm{~g}$ de leucine par litre de culture (Akashi et al., 1978). Ils peuvent également produire des nucléotides utilisés dans l'industrie pour accentuer les arômes (Phaff, 1981) : acide 5'-inosinique et acide 5'-guanylique. Ils sont également aptes à convertir certains stéroïdes. Corynebacterium simplex multiplie de 3 à 5 fois l'effet thérapeutique de la cortisone et de l'hydrocortisone en introduisant spécifiquement une double liaison supplémentaire au cycle A (Nobile et al., 1955).

L'étude de cette transformation en procédé semi-continu, à l'aide de cellules immobilisées, est prometteuse (Ohlson et al., 1978), la capacité de transformation étant de $0,5 \mathrm{~g}$ de stéroïdes par jour et par mg de gel (poids sec). Les transformations de stéroïdes par les Corynebacteriaceae sont examinées dans la revue de Charney (1966).

\section{PRESENCE DE B. LINENS DANS LES FROMAGES}

Kelly (1937) dans sa description de la flore microbienne de surface du Limburger, mentionne la présence de taches rouges connue déjà par Weigmann (1933). Cependant, Wolff (1909) fut le premier à étudier les micro-organismes responsables de cette couleur. En 1910, comme 


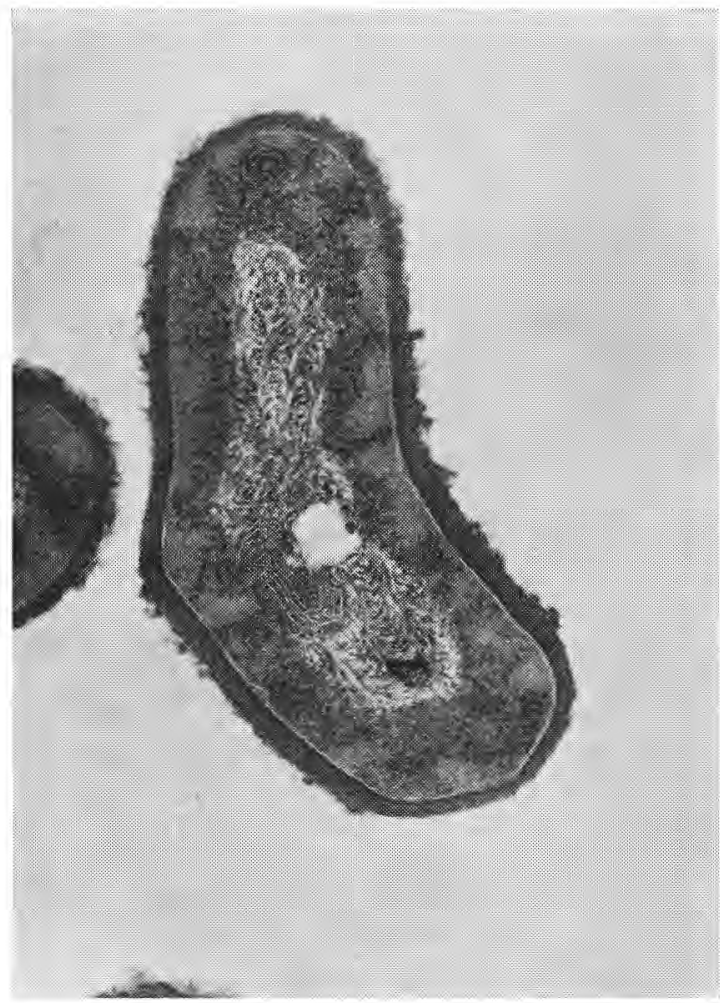

Brevibacterium linens ATCC 9175.

Cellule en forme

"bending ". $(\mathrm{G}=62000)$.

(Photographie de Micheline Rousseau).

suggéré par Weigmann, Wolff nomme cet «Organismus IX » Bacterium linens, Depuis, de nombreuses observations mentionnent Bacterium linens sur des fromages : Filipovic (1923) lui attribue l'odeur et la flaveur typiques de 3 types de fromages de Limburg (Schwarzenberger, Hagenberger, Romadour). Kelly et Marquardt (1939) le retrouvent sur des Port-Salut affinés. Sansonnetti (1930) lui attribue la flaveur particulière du Camembert.

En effet, $B$. linens est un organisme essentiel intervenant au cours de l'affinage de nombreux fromages à pầte molle (Brie : Wolff, 1909 ; Munster, Livarot et Pont-Lévêque : Veisseyre, 1975), à pâte cuite entretenus humides (présence d'une "morge ", Comté : Rose, 1981 ; Gruyère : Dommen, 1957) et à pâte pressée non cuite (Tilsit : Dommen, 1954 a et 1954 b).

La présence de bactéries oranges halotolérantes est souvent mentionnée dans d'autres travaux mais les germes sont rarement identifiés au rang d'espèce (Accolas, Melcion et Vassal, 1978). Dans ce mémoire nous nous sommes donc limités à la citation de travaux où $B$. linens est nommé. Du fait de sa nature aérobie stricte (Keddie et Cure, 1977) 
il a été trouvé naturellement en plus grand nombre à la surface des fromages, soit en combinaison avec des moisissures (par exemple sur le Camembert), soit avec des levures (par exemple sur le fromage de Limburg) (Toolens et Koning-Theune, 1970).

Dans un certain nombre de cas, il existerait en surface des fromages une symbiose entre les levures et $B$. linens (Purko et al, 1951a). En effet, dans le cas du Trappiste ou du Limburger, on observe que les levures métabolisent le lactate et entraînent une remontée du pH du caillé, ce qui permet à $B$. linens de s'implanter. De plus, les levures produisent in situ une quantité significative d'acide pantothénique, de riboflavine et de niacine, vitamines nécessaires à la croissance de nombreuses souches de $B$. linens. D'autre part, le remplacement progressif des levures par Bacterium linens a été notamment décrit dans les fromages "bleus " (Morris, Combs et Coulter, 1951 ; Hartley et Jezeski, 1954) où sa présence semble provoquer le développement de l'arôme du fromage.

Kayser fut l'un des premiers à noter, en 1931, l'action inhibitrice des "Ferments du rouge " (dénomination empirique de Brevibacterium linens) sur la croissance des moisissures sur les fromages. En effet, des études plus récentes ont montré que $B$. linens était apte à inhiber la croissance de champignons, en particulier ceux responsables de l'altération de denrées alimentaires (Lewis, 1982). Une telle action anti-fongique serait corrélée à la production de thiols (Lewis, 1980). Cette activité antibiotique a également été décelée dans de vieux fromages affinés (Grecz, Dack et Hedrick, 1961) et peut inhiber la germination de spores de Clostridium botulinum type A (Grecz et al., 1959). La substance impliquée était non volatile, peu oxydable par l'air, résistante à la lumière, stable de $\mathrm{pH} 2,0$ à 12,0 et soluble dans l'eau et l'éthanol. Elle était capable d'inhiber la croissance de nombreux germes Gram - et Gram + dont certains responsables d'intoxications alimentaires (Staphylococcus aureus, Bacillus cereus) (Grecz, Dack et Hedrick, 1962).

Aspergillus parasiticus, moisissure que l'on peut trouver sur le Cheddar et le Tilsit notamment, produit une aflatoxine (carcinogène hépatique) léthale pour la plupart des animaux testés par Marth (1967). Cette production d'aflatoxine est partiellement inhibée par la présence de B. linens (Weckbach et Marth, 1977). Selon ces auteurs, $B$. linens ne dégraderait pas l'aflatoxine comme l'avaient suggéré Shih et Marth (1972), mais agirait en tant que compétiteur dans la croissance de la moisissure.

$B$. linens est également capable de dégrader certains pesticides du type D.D.T. (1,1,1-trichloro-2,2-bis (p-chlorophényl) éthane) qui peuvent se retrouver dans les fromages (Ledford et Chen, 1969). B. linens est employé, avec d'autres micro-organismes, pour éliminer les composés phosphorés des eaux résiduaires. Cet emploi a fait l'objet de deux brevets par l'université de Nagoya (Udaka et Shoda 1979 ; 
Université de Nagoya, 1978). Les protéases de B. linens sont également employées dans le décapage des peaux (Orlita, Urbanova et Lacnakova, 1978).

\title{
III. POSITION \\ TAXONOMIQUE DE BREVIBACTERIUM LINENS
}

\author{
III.1. PROBlèmes GÉNÉRAuX DE LA ClASSIFICATION DES BaCtÉRIES \\ CORYNÉFORMES.
}

Dans leur ouvrage de microbiologie laitière, Foster et al. (1961) décrivent un certain nombre de caractères de l'espèce Brevibacterium linens. Il s'agit d'une bactérie Gram +, immobile, non sporulante, de $0,6 \times 2,5 \mu \mathrm{m}$, aérobie stricte, catalase + et oxidase - , comme la plupart des bactéries Gram + (Steel, 1961). Yamada et Komagata (1972a) précisent en outre que B. linens est uréase - , que les cellules ne présentent pas de granules métachromatiques, et sont capables d'hydrolyser la gélatine, le lait (Sharpe et al., 1977), mais pas l'amidon (Crombach, 1974b).

La classification et l'identification des bactéries corynéformes (dont $B$. linens) sont demeurées longtemps confuses et difficiles. Leur morphologie particulière, bâtonnets parfois en forme de massue (comme le suggère le nom grec « coryne $»=$ massue), isolés ou groupés en palissades, formant des "lettres ", les faisait traditionnellement classer comme un groupe d'organismes apparentés et placés dans le genre Corynebacterium. Mais les critères " classiques » avaient peu de valeur pour séparer les différents taxons (groupe de caractères donnant trop de résultats négatifs comme l'utilisation des sucres avec production d'acide), donc les genres étaient très mal définis. La conséquence directe en était que de nouvelles souches isolées pouvaient être placées, avec des justifications identiques, dans tel ou tel autre genre entraînant la subdivision en nouvelles espèces sur la base de critères trop fragiles.

Les méthodes modernes de taxonomie (taxonomie numérique, analyse de parois, composition en lipides, composition en bases des acides nucléiques ainsi que la détermination des taux d'hybridation), ont radicalement changé cet état de choses et une classification plus solide semble devoir émerger. Il devient fréquent de redéfinir des genres et de voir reclasser des espèces (Collins, Jones et Kroppenstedt, 1983).

Le genre Corynebacterium fut créé en 1896 par Lehmann et Neumann afin d'harmoniser la position taxonomique du bacille diphtérique avec celle de quelques autres espèces parasites de l'animal. Le genre fut principalement défini sur des critères de morphologie et de réactions colorées. Le terme " corynéforme " fut, quant à lui, introduit pour la première fois, par Jensen en 1952. L'on doit noter, 
à ce niveau, que la morphologie des bactéries corynéformes varie durant le cycle de croissance, et ceci parfois de façon très importante, et qu'elle dépend, de plus, des conditions de culture dans lesquelles on les place (Cure et Keddie, 1973 ; Veldkamp, 1970). B. linens présente ces transformations. La situation taxonomique n'est pas beaucoup plus claire en 1968. La $8^{\mathrm{e}}$ édition du Bergey's manual of determinative bacteriology classe dans la section « Bactéries du groupe corynéforme "les genres suivants : Corynebacterium, Arthrobacter, Cellulomonas, ainsi que Brevibacterium et Microbacterium, considérés comme "Genera incertae sedis".

Actuellement la taxonomie numérique est plus utilisée grâce aux moyens de calcul modernes (micro-ordinateurs). La méthode consiste à comparer un grand nombre de caractères phénotypiques d'un organisme avec les mêmes caractères phénotypiques d'un autre organisme. Le degré de similitude ou de différence entre eux est alors enregistré. Les organismes sont ainsi classés en groupes sur cette base. Les bactéries qui ont un grand nombre de caractères en commun ont donc un haut degré de similitude. Ce regroupement peut permettre l'élaboration d'une classification. Dans le cas des bactéries corynéformes, la haute confiance autrefois placée en des caractères morphologiques mal définis a contribué à la mauvaise définition taxonomique de ce groupe. A l'encontre de Da Silva et Holt (1965) et de Bousfield (1972), Jones indique (1975) que Brevibacterium est suffisamment distinct pour être reconnu en tant que genre, différent du genre Arthrobacter. Le genre Brevibacterium peut être retenu mais il doit être redéfini comme l'ont suggéré Yamada et Komagata (1972b).

\section{III.2. COMPOSITION DE LA PAROI DE B. LINENS.}

Dès 1956, Cummins et Harris ont suggéré que la composition chimique des parois des bactéries Gram + pouvait être un critère taxonomique. En suivant leurs premières études, la composition des parois est devenue un critère indéniable dans la classification des bactéries corynéformes. En effet, elles présentent la plus grande variation de types de peptidoglycanes de toutes les familles bactériennes (Schleifer et Kandler, 1972). Les analyses de parois semblent donner raison à Jones. En effet, les souches incluses dans l'espèce $B$. linens, révèlent, au cours de leur analyse de paroi, du méso-DAP (1) direct (sans pont interpepditique, groupe A1 $\gamma$ de Schleifer et Kandler), et l'absence d'arabinose et de galactose. Keddie et Bousfield (1980) ont établi que la présence de ribose mentionnée par Keddie et Cure (1977) dans la paroi de B. linens était une erreur. La présence de méso-DAP est confirmée par Harper et Davis (1979) qui trouvent également de l'alanine, les acides glutamique et aspartique, de la glycine et

(1) DAP $=$ acide diaminopimélique. 
de la sérine, par chromatographie bidimentionnelle en couche mince. Yamada et Komagata ne trouvent que des traces d'acide aspartique (1970a) mais indiquent la présence de lysine dans 5 cas sur 8. L'acide muramique et la glucosamine sont toujours présents alors que la galactosamine ne l'est que dans $50 \%$ des souches. Les souches de Brevibacterium linens ne contiennent pas d'acide mycolique (Goodfellow, Collins et Minnikin, 1976), absence confirmée par Keddie et Cure (1977) qui, par ailleurs, retrouvent ces acides chez toutes les autres souches de bactéries de type corynéforme examinées.

\section{III.3. CoMposition LIPIDIQUE.}

La composition lipidique de $B$. linens est particulière. En effet cette bactérie contient des acides gras à chaîne branchée, du phosphatidylinositol et du phosphatidylinositol mannoside dans ses lipides polaires (Komura et al., 1975).

Cet argument est de valeur puisque l'analyse lipidique a prouvé son grand intérêt dans la classification et l'identification des bactéries de type corynéforme (Goodfellow, Collins et Minnikin, 1976 ; Yamada et al., 1976 ; Collins et al., 1977 ; Collins, Goodfellow et Minnikin, 1979 ; 1980a ; Collins et Jones, 1980 ; Collins, Keddie et Kroppenstedt, 1983 ; Collins et Kroppenstedt, 1983). L'analyse par chromatographie gazliquide montre que les acides gras majoritaires sont les acides 14méthyl hexadécanoïque (antéiso-C17) et 12-méthyl tétradécanoïque (antéiso C 15) (Collins et al., 1980b). Une autre caractéristique de $B$. linens serait la présence majoritaire $(80 \%)$ de dianté-isononacosène (diméthyl-3,25 heptacosène-13) dans ses hydrocarbures peu polaires (Dagonneau et Kuzdzal-Savoie, 1978).

\section{III.4. AsPects GÉNÉtioues.}

Le génome de $B$. linens à une taille de 1,6.109 (ATCC 9174) à 2,0. $10^{9}$ Daltons (ATCC 9175) (Crombach, 1978).

La composition en bases de l'ADN (2) est habituellement donnée sous la forme du $\mathrm{G}+\mathrm{C} \%$. C'est le nombre total de moles de guanine (G) et de cytosine (C), exprimé en pourcentage du nombre total de moles de chacune des bases, guanine, cytosine, adénine et thymine, présentes dans l'ADN. Il peut être calculé à partir du point de fusion de l'ADN purifié en utilisant la formule de De Ley (1970). Il peut aussi être calculé en connaissant la densité de flottaison.

Dans l'étude de Crombach (1972) sur Brevibacterium et d'autres bactéries corynéformes isolées de fromages ou de poissons, on constate que les valeurs du $\mathrm{G}+\mathrm{C} \%$ varient de 46 à $73 \%$ indiquant encore

(2) $\quad \mathrm{ADN}=$ acide désoxyribonucléique. 
un fois l'hétérogénéité de ce groupe. Quoiqu'il en soit, l'espèce type Brevibacterium linens apparaît homogène et ses représentants ont une valeur de $\mathrm{G}+\mathrm{C} \%$ autour de 61 à $64 \%$ (Skyring et Quadling, 1970 ; Yamada et Komagata, 1970b ; Bousfield, 1972 ; Crombach, 1972). Les valeurs de $G+C \%$ des bactéries de poissons marins sont de 60 à $64 \%$ et couvrent donc le même intervalle que les souches répertoriées de $B$. linens (Crombach 1974a). Les bactéries corynéformes non-oranges isolées de fromages ont des $\mathrm{G}+\mathrm{C} \%$ de 56 à $67 \%$ (Crombach, 1972). En plus des similitudes physiologiques et morphologiques, ceci suggère des relations génétiques étroites entre $B$. linens et les bactéries corynéformes oranges de fromages et des poissons d'eau de mer.

La composition en bases de l'ADN est une aide, mais c'est une information limitée pour la taxonomie des micro-organismes. Elle ne donne que les dissimilitudes génétiques évidentes entre des organismes suffisamment éloignés en valeurs de $\mathrm{G}+\mathrm{C} \%$. Deux bactéries ayant la même composition en base de leur ADN peuvent être, mais ne sont pas nécessairement, étroitement apparentées. Par contre, les hybridations ADN-ADN sont une preuve plus directe de l'homologie génétique de bactéries. Ces relations sont exprimées par le taux de complémentarité des séquences nucléotidiques des chromosomes qui peut être déterminé par réassociation de simples fragments d'ADN dans des conditions strictement standardisées. Deux segments d'ADN hétérologues dénaturés sont capables de réassociation seulement si ils ont suffisamment de séquences nucléotidiques complémentaires. Ainsi, le très faible taux d'hybridation entre Arthrobacter globiformis AC 405 et B. linens ATCC 9175 corrobore l'opinion de Mulder qui tend à considérer l'espèce $B$. linens comme une espèce distincte que l'on ne doit pas placer dans le genre Arthrobacter (Mulder et al., 1966).

Le degré d'homologie très élevé (supérieur à $75 \%$ ) entre B. linens B 42 et plusieurs autres bactéries corynéformes oranges, montre le caractère homogène de cette espèce (Crombach 1978). En plus des différences de $G+C \%$ (Crombach 1972) et de caractères physiologiques (Mulder 1966), les bactéries corynéformes non oranges isolées de fromages ne montrent que $11 \%$ d'hybridation avec une souche test $B$. linens, indiquant ainsi une dissimilitude génétique marquée avec les bactéries corynéformes oranges.

Le récent séquençage nucléotidique de l'ARN (3) $16 \mathrm{~S}$ ribosomique d'organismes représentatifs des différents genres classés parmi les bactéries corynéformes est un argument supplémentaire à la formation du genre Brevibacterium (Stackebrandt, Lewis et Woese, 1980) autour de l'espèce $B$. linens.

(3) $\quad$ ARN $=$ acide ribonucléique. 


\section{III.5. LA PIGMENTATION DE BREVIBACTERIUM LINENS}

La pigmentation des colonies est un critère bien connu et depuis longtemps utilisé par les microbiologistes dans l'identification des micro-organismes. Le pigment jaune-orange de $B$. linens qui lui vaut le nom de "ferment du rouge " est une caractéristique relativement stable, même si son intensité peut dépendre de l'oxygène présent, de la composition du milieu ou de l'âge de la culture (Albert, Long et Hammer, 1944).

Grecz et Dack (1961) ont proposé l'utilisation d'un test simple, mettant en jeu le(s) pigment(s) de B. linens, comme critère taxonomique. La réaction avec des bases fortes semble particulièrement intéressante. Une goutte de soude $5 \mathrm{~N}$ ou de potasse $5 \mathrm{~N}$ sur une colonie provoque une coloration rouge-carmin immédiate. Cette coloration est stable et hautement spécifique. Avec les autres germes colorés testés (Staphylococcus aureus, S. epidermidis, Micrococcus flavus, $M$. citreus, Sarcina lutea, Mycobacterium phlei) cette méthode ne provoque pas l'apparition de cette coloration. La suggestion de Grecz et Dack (1961) fut reprise par Jones, Watkins et Erikson (1973).

Ces auteurs ont inclus 93 souches (dont certaines colorées en jaune-orange sans être $B$. linens) dans une classification de bactéries corynéformes. Cinq souches seulement donnèrent la réaction colorée escomptée : les 2 souches de collection de $B$. linens et 3 autres souches morphologiquement proches de $B$. linens. Mais une étude de taxonomie numérique, menée en parallèle, montrait $85 \%$ de similitude entre les 5 souches, attestant l'exactitude du test proposé par Grecz et Dack (1961).

La membrane cellulaire de $B$. linens semble posséder un pigment de la famille des caroténoïdes qui pourrait jouer un rôle dans la classification taxonomique après détermination de sa structure (Jones, 1975). Ce caroténoïde typique de $B$. linens semble être phénolique (Fautz et Reichenbach, 1980).

La moitié des souches testées par Mulder et al. (1966) ont leur pigmentation dépendante de la lumière et ceci exclusivement pendant la croissance. En effet, des cultures âgées incubées dans le noir, ne se colorent que très peu après exposition à la lumière. De plus, l'oxygène et des conditions nutritionnelles définies peuvent avoir un effet sur la pigmentation. Le dessèchement des boîtes de gélose amplifierait la coloration ainsi que l'addition de carbonate de calcium ou de $\mathrm{NaCl}$ à $3 \%$. Par contre, 6 semaines d'exposition à la lumière feraient disparaître la pigmentation.

Crombach (1974 b) a étudié également l'influence de $\mathrm{NaCl}(4 \%)$ et de la lumière sur la pigmentation. Il a confirmé la production de pigment par exposition à la lumière mais le chlorure de sodium semblait avoir peu d'effet. Sur les 150 souches étudiées par El Erian 
et El Gamal (1975), 72 ont exigé la présence de lumière pour synthétiser leur pigment.

Très récemment Kohl, Achenbach et Reichenbach (1983) ont montré l'existence de 3 pigments chez Brevibacterium linens. Ce sont des caroténoïdes aromatiques. Les structures, élucidées par spectrographie de masse, sont les suivantes :

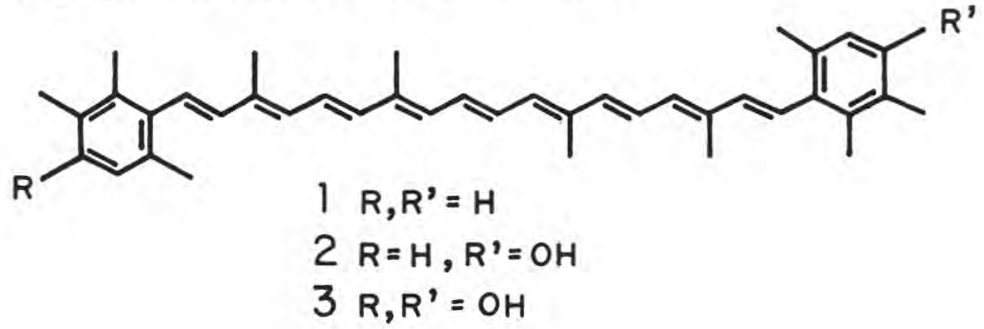

$1=$ isorenieratène.

2 = 3-hydroxy-isorenieratène.

$3=3,3^{\prime}$ dihydroxy-isorenieratène.

Les pigments 2 et 3 n'ont été, à ce jour, mis en évidence que chez B. linens (Kohl et al., 1983), et chez Streptomyces mediolani (Arcamone et al., 1970). Cette distribution écologique restreinte pourrait être exploitée dans la taxonomie si les futures investigations chez les autres bactéries corynéformes s'avèrent négatives. Ces mêmes travaux ont déjà montré que Arthrobacter globiformis était dépourvu de ces pigments.

III.6. AUTRES PROPRIÉTÉS UTILISABLES POUR L'IDENTIFICATION DE B. LINENS

La production de méthanethiol $\left(\mathrm{CH}_{3} \mathrm{SH}\right)$ à partir de L-méthionine par Brevibacterium linens pourrait être un critère taxonomique important, ou tout du moins, un élément d'importance pratique certaine (Sharpe et al., 1977). Pitcher et Noble (1978), dans une étude clinique de la flore de la peau humaine, ont mis en évidence des bactéries dont la composition de paroi était identique à celle de $B$. linens. La moitié de ces bactéries produisaient du méthanethiol. Ces auteurs posent l'éventuelle corrélation entre la présence de ces germes et leur pouvoir de dégradation de la méthionine avec l'odeur du corps humain, ou au moins une contribution à cette odeur.

La production de désoxyribonucléase extracellulaire était une caractéristique commune à toutes les souches de $B$. linens testées par Sharpe et al. (1977) et à cinq souches sur les huit étudiées par Yamada et Komagata (1972a).

Komagata, Yamada et Ogawa (1969) ont classé les bactéries corynéformes en trois groupes selon leur mode de division. B. linens (ATCC 
8377) appartient au troisième groupe qui se divise selon le type "fléchissant " ( bending type "). Après élongation, les cellules se plient au niveau du septum et présentent une forme en $\mathrm{V}$ caractéristique (voir photographie p. 191).

\section{III.7. CONCLUSION}

Le type du peptidoglycane (méso-DAP direct), l'absence d'acide mycolique et d'arabinogalactane sont trois arguments en faveur de la reconnaissance de l'espèce Brevibacterium linens. Les travaux de Fiedler, Schäffler et Stackebrandt (1981) apportent d'autres éléments importants. La présence de galactose (souvent), de glucose (toujours) et de rhamnose (parfois) est notée dans les polysaccharides de la paroi. Des acides teïchoiques, jusqu'alors inconnus chez les bactéries corynéformes, sont présents chez $B$. linens. De plus, ils sont d'un type particulier. Ces acides teïchoiques sont composés soit de polyglycérolphosphate et de polyribitolphosphate, soit de polyglycérolphosphate et de polymannitolphosphate. Dans cette même étude, Fiedler et al. montrent l'absence de relation génétique étroite entre $B$. linens et Arthrobacter globiformis par des études de réassociation entre ADN $23 \mathrm{~S}$ et ARN ribosomal $16 \mathrm{~S}$. Ces auteurs proposent de classer dans l'espèce $B$. linens les bactéries corynéformes dont l'analyse indiquerait la présence de phosphate, de glycérol et de méso-DAP.

Enfin, comme nous l'avons décrit ci-dessus, la présence de pigments particuliers permet de mieux identifier B. linens.

\section{EXIGENCES NUTRITIONNELLES}

\section{IV.1. Problème de L'isolement et du dénombrement}

Les espèces pathogènes sont cultivées depuis de nombreuses années (Mueller, 1940 ; Wilson et Miles, 1964). Jensen (1952) et Conn et Dimmick (1947) ont montré que les besoins spécifiques des bactéries de type corynéforme sont complexes.

Des études de nutrition ont été également menées sur les espèces pathogènes pour les plantes (Starr, 1949 ; Mohanty, 1951 ; Lachance, 1960 ; 1962), pour les animaux (Mueller, 1940 ; Wilson et Miles, 1964) et pour les espèces se retrouvant dans les sols (Grainger et Keddie, 1963 ; Keddie et Cure, 1977). Les études de nutrition sur les bactéries corynéformes saprophytes sont peu nombreuses (Skerman et JayneWilliams, 1966 ; Owens et Keddie, 1968 ; Veldkamp, 1970) et n'incluent que rarement $B$. linens. La recherche d'un milieu de culture apte à favoriser sélectivement la croissance de $B$. linens a débuté par l'emploi d'un extrait de l'un de ses milieux naturels : le fromage (Albert et al., 1944). Mais ce type de milieu permet la croissance d'un grand nombre de micro-organismes sans discerner particulière- 
ment $B$. linens des autres bactéries qui donnent des colonies brunorange (Staphylococcus aureus, $S$. epidermidis, Micrococcus flavus, $M$. citreus, Mycobacterium phlei et Sarcina lutea) (Toolens et KoningTheune, 1970). L'assimilation du glucose sans production d'acide (Kelly, 1937) a été mise à profit pour discerner $B$. linens des autres micro-organismes présents dans la flore d'affinage de surface des fromages. Toolens et Koning-Theune (1970) utilisent le carbonate de calcium dans un milieu solide glucosé. Les colonies productrices d'acide sont repérées par la zone claire environnante due à la dissolution du $\mathrm{CaCO}_{3}$. La pimafucine $(0,02 \%)$ est ajoutée afin d'éviter la croissance des levures et moisissures. Ce milieu ne peut pas convenir à la numération des $B$. linens chez les poissons de par la présence d'autres espèces qui ne produisent pas d'acide. Afin d'étudier la morphologie des bactéries corynéformes de toutes provenances, Cure et Keddie (1973) ont proposé un milieu défini. On peut y voir le cycle de transformations morphologiques de $B$. linens (coques bâtonnets - coques : $6 \mathrm{~h} ; 24 \mathrm{~h}$ et 7 jours de culture), et observer son mode de division.

\section{IV.2. UTILISATION DE L'AZOTE PAR B. LINENS ET EXIGENCES VITAMINIQUES}

Kelly note l'utilisation de Bacto peptone comme source de carbone et d'azote, mais l'asparagine, le sulfate d'ammonium et le nitrate d'ammonium ne sont pas utilisés (Kelly et Marquardt, 1939). Bousfield (1972), utilisant un milieu solide, indique que $B$. linens et les bactéries corynéformes oranges de fromages sont capables d'utiliser l'azote inorganique. Crombach $(1974$ b) critique la méthode où, selon lui, l'agar apporte des composés organiques azotés. El Erian et El Gamal (1975), indiquent que seulement 21 souches de B. linens sur 150 testées sont capables d'assimiler l'azote sous forme inorganique, les autres souches utilisant l'azote sous forme organique avec ou sans vitamines dans le milieu.

Mulder et Antheunisse (1963) ont examiné la culture de B. linens en comparaison avec celle des souches d'Arthrobacter isolées de sols, de boues activées et de fromages. La souche de $B$. linens, cultivée en milieu de base exigeait l'addition d'hydrolysat de caséine (sans vitamines, $3,57 \mathrm{~g} / 1$ ) et sa croissance était stimulée par de l'extrait de levure $(3,5 \mathrm{~g} / 1)$, " probablement grâce aux vitamines se trouvant dans cet extrait ". L'addition d'acides aminés et d'extrait de levure avait peu d'influence sur la morphologie des cellules.

A l'opposé du genre Arthrobacter, aux exigences connues (en vit. B12, notamment) (Lochhead et Thexton, 1951 ; Lochhead et Burton, 1955 ; Owens et Keddie, 1968), les informations sur B. linens sont fragmentaires. Mulder et Antheunisse (1963) rapportent que B. linens métabolise l'azote sous forme inorganique en présence d'un mélange 
de vitamines (biotine 2 , acide folique 20 , riboflavine 100 , thiamine 100 , pyridoxine chlorhydrique 100 , acide nicotinique 100 , pantothénate de calcium 100 , acide p-aminobenzoïque 100 , cyanocobalamine $\left(B_{12}\right)$ $1 \mu \mathrm{g}$ par litre), alors que les corynébactéries phytopathogènes exigent l'azote sous forme d'acides aminés.

Dans leur étude sur la morphologie des bactéries corynéformes, Cure et Keddie (1973) supplémentaient leur milieu en vitamine $B_{12}$ et extrait de levure en indiquant que ce dernier enrichit le milieu en vitamines autres que $\mathrm{B}_{12}$.

Sur 4 souches de B. linens examinées par Mulder et al. (1966), 3 n'emploient l'azote sous forme organique (acide glutamique ou casamino-acides), qu'en présence de vitamines. La plupart des souches " oranges " isolées de fromages ou de poissons de mer sont incapables d'utiliser l'azote sous forme inorganique et exigent de plus un mélange vitaminique. (Ces souches sont considérées comme étant B. linens ou très proches).

Iya et Frazier (1949) ont montré que Bacterium linens pouvait se multiplier sur un milieu où une levure avait préalablement cultivé. Purko, Nelson et Wood (1951a) ont rapporté que des levures isolées de fromages de Limburg secrétaient de l'acide pantothénique, de la niacine, de la riboflavine et de la biotine. Ces auteurs corrèlent la multiplication de $B$. linens à cette production de vitamines. Meyer (1949) observe que 8 souches de $B$. linens (sur 25 testées) requièrent l'acide pantothénique pour leur croissance; 11 souches exigeaient la présence de 8 vitamines du groupe B. Purko, Nelson et Wood (1951b, 1953) ont montré la synergie d'action de la biotine, de l'acide paraamino-benzoïque et de l'acide pantothénique sur la croissance de $B$. linens dans un milieu de base chimiquement défini. L'acide paraamino-benzoïque permet une multiplication moins rapide mais plus importante que l'acide pantothénique, ceci en présence ou en absence de biotine. La biotine seule n'est pas indispensable pour la croissance. Si Bacterium linens était cultivé en présence d'une seule des 2 vitamines (acide para-amino-benzoïque ou acide pantothénique), l'autre était synthétisée par le micro-organisme (Purko, Nelson et Wood, 1951b). Ces auteurs admettent l'intervention de chacune de ces vitamines dans la biosynthèse de l'autre. L'acide folique n'était efficace sur la croissance qu'à très haute concentration $(2,8 \mu \mathrm{g} / \mathrm{ml})$. Friedman, Wood et NeIson (1953) développèrent un milieu synthétique dans lequel l'omission de cystine, de méthionine ou de leucine provoquait une forte diminution de la croissance en comparaison au développement en présence des 22 acides aminés testés (comprenant les 20 acides aminés naturels plus de la DL-norleucine et la $\beta$-alanine). La présence ou l'absence d'une des bases puriques ou pyrimidiques avait peu d'effet. Aucun des acides aminés ou base ou autre composé utilisé ne diminue le besoin en acide pantothénique en l'absence d'acide para-amino-benzoïque et vice versa. 


\section{IV.3. UTILISATION DES SOURCES CARBONÉES}

Mulder et al. (1966) utilisant 9 souches de collection de B. linens, trouvent une bonne utilisation du glucose et du glycérol. Le lactose et le saccharose étaient peu utilisés. L'acétate et le lactate étaient les substrats les mieux assimilés. Là encore, l'absorption préférentielle de l'acétate, du lactate ou du glycécol, en contradiction avec les résultats précédents de ces auteurs (Mulder et Antheunisse, 1963) sont imputés à l'utilisation d'un milieu solide. Crombach (1974 b) confirme ces résultats en y ajoutant la non-utilisation du citrate et de l'amidon. Toutes les souches de bactéries corynéformes oranges et de $B$. linens testés par Crombach $(1974 \mathrm{~b})$ alcalinisent le milieu de Hugh et Leifson (1953).

\section{IV.4. Halotolérance}

Brevibacterium linens est une bactérie halotolérante (Stadhouders et Langeveld, 1962). Toutes les souches (150) de B. linens testées par El Erian et El Gamal (1975) se multiplient en présence de $12 \%$ de $\mathrm{NaCl}$. L'halotolérance de ce germe permet son implantation préférentielle dans certains milieux comme les fromages légèrement salés (Camembert : 2 à 2,5\% en $\mathrm{NaCl}$ (Veisseyre, 1975), ou fromage de Limburg (Kelly et Marquardt, 1939) et les océans. Une tolérance de $20 \%$ en $\mathrm{NaCl}$ est constatée en milieu liquide ou solide par Kelly et Marquardt (1939) mais la tolérance habituelle n'excède pas $15 \%$ (Sharpe, Law et Phillips, 1977). Le sel exerce diverses influences sur les cellules. La croissance est notable après 1 mois de culture à $12 \%$ en $\mathrm{NaCl}$ pour les six souches testées par Mulder et al. (1966). L'addition de $\mathrm{NaCl}$ à $4 \%$ permet la croissance de $B$. linens à $\mathrm{pH} 6,0$ qui est normalement nulle. L'augmentation de la consommation d'oxygène à $\mathrm{pH} 5,4$ en présence de $\mathrm{NaCl}$ semblerait provenir d'une activité accrue des enzymes impliquées dans l'oxydation du glutamate (Mulder et al., 1966). La présence du sel à $4 \%$ augmente également la température optimale de croissance de $2,5^{\circ} \mathrm{C}$.

\section{IV.5. TEMPÉRATURE ET PH DE CROISSANCE}

Les souches d'origine laitière présentent une température optimum de croissance de $25^{\circ} \mathrm{C}$ environ (Kelly et Marquardt, 1939), température à laquelle le germe se multiplie même à $\mathrm{pH} 5,85$. Ce $\mathrm{pH}$ est le plus acide accepté par $B$. linens. D'autre part, il peut se multiplier à $\mathrm{pH} 9,5$.

$B$. linens, capable de se diviser à $10^{\circ} \mathrm{C}$ est donc classé dans les bactéries psychrotrophes (Wilkins, 1973). Il ne se multiplie plus à une température de $37^{\circ} \mathrm{C}$ (Kelly, 1937) (Crombach, 1974 b). Par contre, des souches provenant de la peau humaine ont une température optimale de croissance située entre 30 et $37^{\circ} \mathrm{C}$ (Sharpe et al., 1977). 


\section{IV.6. Résistance auX antibiotiques}

$B$. linens s'avère très résistant aux antibiotiques. Sur 42 souches de ferments et de micro-organismes laitiers testés pour leur résistance vis-à-vis de 30 antibiotiques et composés antimicrobiens, seul Lactobacillus dextranicum s'avère plus résistant que $B$. linens (Reinbold et Reddy, 1974). La croissance des 3 souches de $B$. linens n'est pas inhibée par la furadantine à $50 \mu \mathrm{g}$ alors que tous les autres microorganismes testés sont sensibles. Reinbold et Reddy (1974) suggèrent donc l'ajout de cette substance au milieu solide "fromage » utilisé pour isoler B. linens (Albert, Long et Hammer, 1944).

\section{IV.7. AUTRES PROPRIÉTÉS}

La connaissance des besoins nutritionnels de $B$. linens permet l'exploitation industrielle de cette bactérie en culture immergée (Kunz, Hantzschel et Singer, 1980). Le maintien de la température à $24-25^{\circ} \mathrm{C}$ et un apport actif d'oxygène permettent une bonne croissance en fermenteur de 16 l, pour un $\mathrm{pH}$ initial compris entre 6,0 et 7,0. L'étude comparative entre une culture immergée aérée et une culture classique de surface ne montre que peu de différences : même température optimum, même production de catalase, la montée du $\mathrm{pH}$ étant un peu plus importante en fermentation par immersion (Kunz et Singer, 1981), mais les taux de production de cellules sont meilleurs en milieu liquide.

Enfin, comme d'autres bactéries corynéformes, $B$. linens est capable de résister efficacement à de très longues périodes de privation nutritionnelle, ce qui explique en partie leur grande distribution écologique (Boylen et Mulks, 1978 ; Krulwich et Pelliccione, 1979).

\section{ACTIVITES PROTEOLYTIQUES DE BREVIBACTERIUM LINENS}

\section{V.1. ACTIVITÉ PROTÉOLYTIQUE ENDOPEPTIDASIQUE}

Chez B. linens, l'activité protéolytique extracellulaire globale dosée sur la caséine est très variable d'une souche à l'autre ; certaines ne produisent aucune activité dans les surnageants de culture (Friedman et al., 1953). Une telle variation a aussi été observée en utilisant la gélatine comme substrat (Foissy, 1973 ; 1974 a et b). L'activité est surtout importante avec les cultures jeunes (Thomasow, 1950). En général, la présence de glucose n'influence pas la production de protéinase, qui semble aussi indépendante du degré d'aération (Brandl et Petutschnig, 1972). La production est plus forte si le milieu est ajusté au départ à $\mathrm{pH} 7$, plutôt qu'à $\mathrm{pH} 6$ ou 8 , et se poursuit au cours de la phase logarithmique. Une remontée de l'activité peut se pro- 
duire aussi pendant la phase stationnaire (Thomasow, 1950 ; Friedman et al., 1953 a). Ces auteurs ont aussi effectué un fractionnement partiel de l'activité extracellulaire par précipitation fractionnée au sulfate d'ammonium, l'enzyme précipitant dans deux fractions respectivement entre 52 et $68 \%$ et 68 et $100 \%$ de saturation. Le pH optimum de cette activité est 7,2-7,3. Sa température optimum est $38^{\circ} \mathrm{C}$. Une très faible activité peut être encore détectée à $0^{\circ} \mathrm{C}$ ou $60^{\circ} \mathrm{C}$. Cette préparation enzymatique n'était pas affectée par la présence de cations $6,6 \times 10^{-4} \mathrm{M}$ tels que $\mathrm{Ca}++, \mathrm{Zn}++, \mathrm{Fe}++, \mathrm{Mn}++, \mathrm{Mg}++, \ldots$ ni par celle des agents réducteurs $6,6 \times 10^{-4} \mathrm{M}$ tels que la cystéine, le thioglycolate de sodium, l'acide ascorbique, etc. Cette protéinase extracellulaire montre une certaine spécificité pour les protéines du lait. En effet, en dehors des caséines, elle ne montre une activité que sur les protéines séminales et n'attaque donc pas ni la sérum albumine bovine, ni la $\gamma$-globuline, ni la $\beta$-lactoglobuline, ni l' $\alpha$-lactalbumine. Les caséines sont hydrolysées dans l'ordre préférentiel décroissant suivant : caséine entière obtenue par centrifugation, caséine isoélectrique, $\beta$-caséine (Friedman et al., 1953 a). L'hémoglobine n'est attaquée qu'après dénaturation thermique (Tokita et Hosono, 1972). Sur d'autres souches, un fractionnement électrophorétique a pu montrer la présence d'au moins trois activités extracellulaires (Foissy, 1973).

En général, l'activité protéolytique globale intracellulaire est beaucoup plus faible que l'activité extracellulaire (Thomasow, 1950 ; Friedman et al., 1953 a) et elle est due en majeure partie aux activités exopeptidasiques car les extraits cellulaires attaquent plus fortement les peptides que la caséine. Cependant, certaines souches présentent des activités endopeptidasiques intracellulaires fortes (Foissy, 1973).

\section{V.2. ACTIVITÉS EXOPEPTIDASIQUES}

\section{V.2.1. Exopeptidase extracellulaire.}

Une aminopeptidase extracellulaire a été purifiée chez Brevibacterium linens ATCC 9174 après croissance dans un milieu complexe (Foissy, 1978 a). L'apparition de cette activité (dosée sur la L- $\alpha$ Leucyle4-nitroanilide) (4) a lieu au cours de la phase logarithmique de croissance. Comme on ne détectait aucune enzyme intracellulaire marqueur (glucose-6-phosphate deshydrogénase) dans le surnageant de culture et que les extraits intracellulaires eux-mêmes étaient dépourvus d'activité sur la L-Leu-NA, la nature extracellulaire de cette aminopeptidase est établie sans ambiguité.

La purification de cette enzyme était difficile, même en utilisant l'électrophorèse préparative, car des activités protéolytiques y restaient associées (Foissy, 1978 a). Son poids moléculaire était estimé à $95000 \pm 5000$ par chromatographie sur Sephadex G 100 et à $48000 \pm 3000$ par électrophorèse en présence de sodium-dodécyl-

(4) L- $\alpha$-Leucyle-4-nitroanilide $=$ L-Leu-NA. 
sulfate. Ceci suggère que l'enzyme native est composée de deux sousunités de poids moléculaire identique. L'électrophorèse analytique peut aussi dissocier ces deux sous-unités, ce qui indique qu'elles ne sont pas liées de façon covalente. D'autre part, son point isoélectrique semble être 4,3 mais cette détermination conduit à l'inactivation de l'enzyme (Foissy, 1978 b).

L'aminopeptidase est rapidement inactivée aux températures supérieures à $50^{\circ} \mathrm{C}$ ainsi qu'aux $\mathrm{pH}$ inférieurs à 3,0 ou supérieurs à 11,5 . A pH 8,0 elle présente une stabilité remarquable mais son activité maximum était obtenue à $\mathrm{pH} 9,6$ entre $26^{\circ}$ et $30^{\circ} \mathrm{C}$. Elle est incapable d'hydrolyser les dipeptides contenant de la D leucine, une forme L étant exigée pour les acides aminés des substrats. Son activité préférentielle décroissante s'établit comme suit : Leu-amide = Leu-Leu $>$ Leu-Met $>$ Leu-Ala $>$ Leu-Tyr $>$ Leu-Gly $>$ Leu-Ser $>$ Leu-Trp $>$ Leu-Val $>$ Phe-Leu $>$ Ser-Leu $>$ His-Lys. Elle attaque faiblement la chaîne $\mathrm{B}$ de l'insuline oxydée bovine en libérant de la phénylalanine et de la valine (Foissy, 1978b).

Cette enzyme purifiée présente la particularité d'être activée par les ions $\mathrm{Co}++$. D'autre part, elle est inhibée par les métaux lourds (particulièrement par les ions $\mathrm{Cd}++$ et à moindre degré par les ions $\mathrm{Hg}++, \mathrm{Pb}++$ et $\mathrm{Cu}++$ ), les chélateurs (EDTA, 8-hydroxyquinoline, 1,10-phénanthroline), les agents réducteurs, certains acides aminés (histidine, sérine, acide glutamique, acides aminés aromatiques) et certains alcools, (éthanol, propanol, butanol et alcool amylique) (Foissy, $1978 \mathrm{c}$ ).

\section{V.2.2. Exopeptidases intracellulaires.}

Après lyse des cellules et séparation électrophorétique des protéines des extraits, plusieurs exopeptidases peuvent être mises en évidence en utilisant différents dipeptides. En particulier, chez la souche $B$. linens ATCC 9174, 6 peptide-hydrolases ont été séparées (Torgersen et $\mathbf{S} \varnothing$ rhaug, 1978). Chez 6 autres souches, jusqu'à 18 bandes présentant une activité dipeptide-hydrolase peuvent être séparées ( $\varnothing$ rhaug, 1981) mais on peut supposer que plusieurs d'entre elles résultent d'une modification par autoprotéolyse des extraits au cours des manipulations ou de phénomènes d'association-dissociation entre protéines.

\section{ACTIVITES LIPOLYTIQUE ET ESTERASIQUE DE BREVIBACTERIUM LINENS}

La présence d'une lipase active sur une émulsion d'huile d'olive a été montrée dans des surnageants de culture de $B$. linens en milieu complexe (San Clemente et Vadhera, 1967). Ce résultat n'a pas été confirmé par Sørhaug et Ordal (1974) qui, en utilisant plusieurs souches, n'ont pas retrouvé d'activité estérasique ou lipasique extra- 
cellulaire. Seules les suspensions cellulaires sont actives sur la tributyrine, la triacétine ou le méthyl-butyrate. Comme les globules de l'émulsion sont plus grandes qu'une cellule bactérienne et qu'on ne peut envisager de phénomènes de transport, les auteurs ont postulé que les sites actifs sont localisés sur (ou à l'intérieur de) la paroi cellulaire. Avec les 5 souches utilisées, l'activité sur la tributyrine est la plus faible. L'activité de cellues lavées dans $5 \%$ de $\mathrm{NaCl}$ est supérieure à celle de cellules lavées dans l'eau (sauf pour la souche ATCC 8377 sur la triacétine). La présence de ces enzymes explique que l'addition d'huile de beurre dans un milieu supportant la croissance de $B$. linens, conduit à la production des acides acétique, n-butyrique et caproïque (Hosono, 1968 b). Les cellules non proliférantes produisent aussi des acides gras volatils à partir de la matière grasse du beurre, de pH 5 à 8,80 ; l'optimum pour la production étant obtenu à $\mathrm{pH} 7,0$. Ce sont les acides acétique, n-butyrique et caproïque qui sont détectés en plus grandes quantités. La production des acides isobutyrique et iso-valérique est très faible, celle des acides propionique et n-valérique est nulle dans les conditions expérimentales décrites (Hosono, 1968 b).

\section{PRODUCTION DE SUBSTANCES VOLATILES DEGRADATION DES ACIDES AMINES}

Les premiers travaux ont montré que, sur milieu complexe, $B$. linens produit de plus grandes quantités de bases volatiles que d'acides volatils ou de substances neutres. Parmi les acides gras, ce sont surtout les acides acétique, iso-valérique et caproïque qui sont mis en évidence. Parmi les substances neutres volatiles, 3 composés carbonylés et 4 alcools ont été déterminés : formaldéhyde, acétoaldéhyde, acétone, éthanol, iso-propanol, n-propanol et iso-butanol (Tokita et al., 1966). Ces substances ont pour origine en particulier les acides aminés : l'acide acétique étant produit à partir de l'alanine, de la leucine ou de la glycine, l'acide iso-valérique vient de la leucine et l'acide caproïque aurait pour origine la cystine, l'alanine ou l'asparagine (Hosono, $1968 \mathrm{a}$ ). En général, le $\mathrm{pH}$ optimal pour la production de ces substances se situe à la neutralité ou dans une zone de faible alcalinité. Des acides gras volatils peuvent évidemment être aussi produits à partir des sucres par B. linens (Hosono, $1968 \mathrm{~b}$ ). Le glucose et le galactose sont beaucoup plus favorables que le lactose. En général, en présence de glucose, on obtient plus d'acides (acétique à caproïque) qu'en présence de galactose.

Les voies générales du catabolisme des acides aminés par les micro-organismes sont connues. Elles impliquent essentiellement des enzymes de type décarboxylase, transaminase, désaminase ou celles 
dégradant la chaîne latérale (Hemme et al., 1982). L'activité désaminante de $B$. linens à l'origine d'une production d'ammoniac, a été montrée chez plusieurs souches. Les acides aminés concernés étaient essentiellement la sérine $>$ la glutamine $>$ l'asparagine $>$ la thréonine $>$ l'arginine $>$ l'alanine $>$ l'acide glutamique $>$ la lysine $>$ la glycine Le $\mathrm{pH}$ de ces désaminations était de 8 environ (Hemme et al., 1982).

La décarboxylation des acides aminés par $B$. linens conduit à la production de bases volatiles spécialement dans les milieux supplémentés en hydrolysat acide de caséine ou en lysine (Hosono et Tokita, 1969 b). Des amines non volatiles (tyramine et histamine) ont été aussi détectées (Tokita et Hosono, $1968 \mathrm{a}$ ). Les quantités de $\mathrm{CO}_{2}$ produit, les plus importantes, étaient obtenues avec la lysine, la tyrosine, l'acide glutamique, l'alanine, la leucine, l'histidine et la glycine. Le $\mathrm{pH}$ optimum de ces décarboxylations était obtenu à 7 excepté pour la glycine et l'histidine (à $\mathrm{pH}$ 6). L'âge physiologique des cellules peut influencer l'activité spécifique des enzymes mais la variation du $\mathrm{pH}$ des milieux au cours de la croissance gêne l'interprétation des résultats. Il semble que l'addition de glucose au milieu favorise ces activités (Hosono et Tokita, 1969 b).

Parmi les acides aminés soufrés, c'est la méthionine qui conduit aux plus fortes quantités de produits volatils soufrés détectables (Tokita et Hosono, 1968 b). B. linens (ou des souches apparentées) produit en particulier du méthane-thiol à partir de cet acide aminé (Sharpe et al., 1977 ; Law et Sharpe, 1978 ; Hemme et al., 1982). Quand $B$. linens croît dans un milieu complexe contenant de la méthionine, les cellules récoltées lorsque le $\mathrm{pH}$ du milieu atteint une valeur de 8 (cellules en bâtonnet en fin de phase exponentielle de croissance) sont les plus fortes productrices de méthane-thiol. Les cellules plus âgées (forme coccoïde) produisent des quantités moindres mais le pH du milieu atteint alors des valeurs supérieures à 8,6. La présence de glucose dans le milieu de culture conduit aussi à une diminution de la production de méthane-thiol (Hemme et al., 1982). En plus de ce composé, $B$. linens dans un milieu complexe peut conduire à la formation de $\mathrm{SH}_{2}$, de diméthyldisulfure et de 2, 3, 4-trithiapentane. Une souche (ATCC 8377) peut produire aussi un thioester : le S-méthyl-thioacétate (Cuer et al., 1979 a) mais en quantité faible.

\section{ROLE DE BREVIBACTERIUM LINENS AU COURS DE L'AFFINAGE DES FROMAGES}

Il a été montré que $B$. linens participe effectivement à la protéolyse des fromages en particulier en libérant des acides aminés libres dans des fromages-modèles de type Trappiste dépourvus de levures (Ades et Cone, 1969). Un rôle dans la protéolyse du fromage 
Limburger a aussi été attribué à B. linens (Tokita et Hosono, 1972), la plupart des souches pouvant entraîner, de plus, une libération d'ammoniac (El Erian, 1972). Dans ce type de fromage, B. linens produirait aussi de nombreux composés carbonylés volatils à partir de la caséine par action combinée de ses protéases et des enzymes du métabolisme (Hosono et Tokita, 1969a). Ces auteurs considèrent, d'autre part, que $B$. linens ne produit pas de composés carbonylés volatils à partir de la matière grasse du lait. B. linens, cultivé sur des tranches de fromages de Limburg, hydrolyse 70 à $80 \%$ des protéines après 3 semaines d'incubation, produisant de grandes quantités d'acides aminés, notamment de la leucine et de la valine (El Erian, 1969).

La présence dans les fromages, à un niveau élevé, de bactéries identifiables à $B$. linens est intéressante car elles sont probablement à l'origine d'une des composantes du goût spécifique des camemberts traditionnels en raison de leur aptitude à dégrader la méthionine avec production de dérivés soufrés (Richard et Zadi, 1983). Ce même rôle leur a été attribué pour le fromage Limburger (Parliment et al., 1982) ou le fromage Trappiste (Grill et al., 1967). Cependant pour le fromage de Camembert, d'autres micro-organismes peuvent participer à la production des composés soufrés volatils car des fabrications pauvres en $B$. linens n'étaient pas moins riches en goût que celles le contenant en nombre élevé (Richard et Zadi, 1983). Dans le fromage de Münster, l'association entre des souches de microcoques et de $B$. linens pourrait conduire à la production de thio-ester (S-méthylthioacétate) contribuant à l'arôme de ce fromage (Cuer et al., 1979 b).

Enfin, il pourrait être attribué à $B$. linens un rôle dans l'apparition des concentrations élevées en phénol dans le fromage Limburger (Parliment et al., 1982), ceci résulterait de son pouvoir de dégradation de la tyrosine, également observé par Sharpe et al. (1977).

\section{Remerciements}

Les auteurs remercient M. J. L. Bergère pour ses suggestions lors de la rédaction du manuscrit.

\section{Bibliographie}

ABd-EL-MaleK (Y.) and Gibson (T.) (1952). - Studies in the bacteriology of milk. III. The corynebacteria of milk. I. Dairy Res., 19, 153-159.

Accolas (J. P.), Melcion (D.) et Vassal (L.) (1978). - Etude de la flore superficielle des fromages de Gruyère et de Beaufort. $\mathrm{XX}^{\oplus}$ Congrès International de Laiterie, Paris, 773-774.

ADEs (G. L.) and CoNe (J. F.) (1969). - Proteolytic activity of Brevibacterium linens during ripening of Trappist-type cheese. J. Dairy Sci., 52, 957-961. 
AKashi (K.), IKeda (S.), Shibai (H.), Kobayashi (K.) and Hirose (Y.) (1978). Determination of redox potential levels critical for cell respiration and suitable for L leucine production. Biotechnol. Bioeng., 20, 27-41.

Albert (J. O.), Long (H. F.) and Hammer (B. W.) (1944). - Classification of the organisms important in dairy products: IV. Bacterium linens. Res. Bull. Iowa agric. Exp. Sta., 328, 235-259.

arcamone (F.), Camerino (B.), Franceschi (G.) e Penco (S.) (1970). - Struttura e sintesi di nuovi carotenoidi fenolici da Streptomyces mediolani. Gazz. chim. Ital., 100, 581-590.

Bousfield (I. J.) (1972). - A taxonomic study of some coryneform bacteria. J. gen. Microbial., 71, 441-455.

Bousfield (I. J.), Gunawardana (Y. W.) and Noble (S.) (1976). - A taxonomic study of some coryneform bacteria from marine sources. Proceed. Soc. gen. Microbiol., 3, 100.

Boylen (C. W.) and MulKs (M. H.) (1978), - The survival of coryneform bacteria during periods of prolonged nutrient starvation. J. gen Microbiol., 105, 323-334.

Brandl (E.) und Petutschnig (K.) (1972). - Orientierende Untersuchungen über die proteolytische und lipolytische Aktivität einiger Brevibacterium linens. Stämme verschiedener Herkunft. Osterr. Milchw., 27, 17-25.

CharNeY (W.) (1966). - Transformation of steroids by Corynebacteriaceae. J. appl. Bacteriol., 29, 93-106.

Collins (M. D.), Pirouz (T.), Goodfellow (M.) and Minnikin (D. E.) (1977). Distribution of menaquinones in Actinomycetes and Corynebacteria. J. gen. Microbiol., 100, 221-230.

Collins (M. D.), Goopfellow (M.) and Minnikin (D. E.) (1979). - Isoprenoid quinones in the classification of coryneform and related bacteria. J. gen. Microbiol., 110, 127-136.

Collins (M. D.), Goodfellow (M.) and Minnikin (D. E.) (1980 a). - Fatty acid, isoprenoid quinone and polar lipid composition in classification of Curtobacterium and related taxa. J. gen. Microbiol., 118, 29-37.

Collins (M. D.), Jones (D.), Keddie (R. M.) and SNeATH (P. H. A.) (1980 b). Reclassification of Chromobacterium iodinum (Davis) in a redefined genus Brevibacterium (Bredd) as Brevibacterium iodinum nom. rev., comb. nov. J. gen. Microbiol., 120, 1-10.

Collins (M. D.) and Jones (D.) (1980), - Lipids in the classification and identification of coryneform bacteria containing peptidoglycans based on 2,4diaminobutyric acid. J. appl. Bacteriol,, 48, 459-470.

Collins (M. D.), Jones (D.) and Kroppenstedt (R. M.) (1983), - Reclassification of Brevibacterium imperiale (Steinhaus) and "Corynebacterium laevaniformans» (Dias and Bhat) in a redefined genus Microbacterium (Orla-Jensen), as Microbacterium imperiale comb. nov. and Microbacterium laevaniformans nom. rev.; comb. nov. System. Appl. Microbiol., 4, 65-78.

Collins (M. D.) and KRopPenstedt (R.) (1983). - Lipid composition as a guide to the classification of some coryneform bacteria-containing an A4 $\alpha$ type peptidoglycan (Schleifer and Kandler). System. Appl. Microbiol., 4, 95-104.

Collins (M. D.), Keddie (R. M.) and KropPenstedt (R. M.) (1983). - Lipid composition of Arthrobacter simplex, A. tumescens and possibly related taxa. System. Appl. Microbiol., 4, 18-26.

ConN (H. J.) and Dimmick (I.) (1947). - Soil bacteria similar in morphology to Mycobacterium and Corynebacterium. J. Bacteriol., 54, 291-303.

Crombach (W. H. J.) (1972). - DNA base composition of soil arthrobacters and other coryneforms from cheese and sea fish. Antonie van Leeuwenhoek, 38, $105-120$. 
CROMBACH (W. H. J.) (1974 a). - Relationships among coryform bacteria from soil, cheese and sea fish. Antonie van Leeuwenhoek, 40, 347-359.

Crombach (W. H. J.) (1974 b). - Morphology and physiology of coryneform bacteria. Antonie van Leetwenhoek, 40, 361-376.

CRombach (W. H. J.) (1978). - DNA base ratio and DNA hybridisation studies of coryneform bacteria, mycobacteria and nocardiae. In Coryneform Bacteria. Ed. Bousfield (I. J.) and Callely (A. G.), London. Academic Press.

Cuer (A.), Dauphin (G.), Kergomard (A.), Dumont (J. P.) and Adda (J.) (1979 a). Production of S-methylthioacetate by Brevibacterium linens. Appl, environm. Microbiol., 38, 332-334.

Cuer (A.), Dauphin (G.), Kergomard (A.), Dumont (J. P.) and Adda (J.) (1979 b). Production of S-methylthioacetate by Micrococcus cheese strains. Agric. Biol. Chem., 43, 1783-1784.

Cummins (C. S.) and Harris (H.) (1956). - The chemical composition of the cell-wall in some Gram-positive bacteria and its possible value as a taxonomic character. J. gen. Microbiol., 14, 583-600.

Cure (G. L.) and KedDie (R. M.) (1973). - Methods for the morphological examination of aerobic coryneform bacteria. In Sampling-Microbiological monitoring of environment. Soc. Appl. Bacteriol., tech, ser. $\mathbf{n}^{\circ}$ 7. Ed. Board (R. G.) and Lovelock (D. W.), London. Academic Press.

Dagonneau (H.) and Kuzdzal-Savoie (S.) (1978). - A comparative study of the fatty acids and hydrocarbons of Brevibacterium linens and Arthrobacter globiformis. XX Internat. Dairy Cong., vol. E., 594-595.

Dommen (G.) (1954 a). - The surface micro-flora of Tilsit cheese. Schweiz. Z. allg. Path., 17, 555-559.

Dommen (G.) (1954 b), - The microbial surface flora of Tilsit cheese. Study of the lipase, phosphatase and protease systems. Landw. Jb. Schweiz., 3, 195-266.

Dommen (G.) (1957), - Surface flora of Gruyère cheese. Landw. Jb. Schweiz, 6, 165-170.

EL-ERTAN (A. F. M.) (1969). - Bacteriological studies on Limburger cheese. Thesis, Wageningen.

EL-ERIAN (A. F.M.) (1972). - Bacteriological studies on Limburger cheese. Neth. Milk Dairy J., 26, 103-106.

El-Erian (A. F. M.) and El-Gamal (S.) (1975). - Morphological characters and nutritional requirements of bacteria belonging to the Brevibacterium linens type. Abstr. Pap., 3rd Conf. Microbiol., Cairo, 4-9 November 1975, 73.

Fautz (E.) and Reichenbach (H.) (1980). - A simple test for flexirubin-type pigments. FEMS Microbiol. Lett., 8, 87-91.

Fiedler (F.), Schaffler (M. J.) and Stackebrandt (E.) (1981). - Biochemical and nucleic acid hybridisation studies on Brevibacterium linens and related strains. Arch. Microbiol., 129, 85-93.

Filipovic (S.) (1923). - Bakteriologische Studien über die Reifung einiger Backsteinkäse. Centbl. Bakteriol., ParasitKde. II Abt., 58, 9-41.

Forssy (H.) (1973). - Einfluss der Bebrütungszeit und des Anzuchmediums auf das electrophoretische Proteinasen-Aktivitätsprofil von Brevibacterium linens, Milchwissenschaft, 28, 692-695.

Forssy (H.) (1974 a). - Examination of Brevibacterium linens by an electrophoretic zymogram technique. J. gen. Microbiol., 80, 197-207.

Foİssy (H.) (1974 b), - A method for demonstrating bacterial proteolytic isoactivities after electrophoresis in acrylamide gels. J. appl. Bacteriol, 37, 133-135. 
Forssy (H.) (1978 a). - Aminopeptidase from Brevibacterium linens: Production and purification. Milchwissenschaft, 33, 221-223.

FoIssy (H.) (1978 b). - Some properties of aminopeptidase from Brevibacterium linens. FEMS Microbiol. Lett., 3, 207-210.

FoIssy (H.) (1978 c). - Aminopeptidase from Brevibacterium linens: Activation and inhibition. Z. Lebensmitt. Unters. Forsch., 166, 164-166.

Foster (E. M.), Nelson (F. E.), Speck (M. L.), Doetsch (R. N.) and Olson (J. C.) (1961). - Dairy Microbiology. Englewood Cliffs, New Jersey. Prentice Hall.

Friedman (M. E.), Nelson (W. O.) and Wood (W. A.) (1953 a). - Proteolytic enzymes from Bacterium linens. J. Dairy Sci., 36, 1124-1134.

Friedman (M. E.), Wood (W. A.) and NeLson (W. O.) (1953 b). - The influence of various metabolites upon the $p$. aminobenzoate-pantothenate interaction in Bacterium linens. J. Bacteriol., 66, 568-571.

Goodfellow (M.), Collins (M. D.) and Minnikin (D. E.) (1976). - Thin-layer chromatographic analysis of mycolic acid and other long-chain components in whole-organism methanolysates of coryneform and related taxa. J. gen. Microbiol., 96, 351-358.

Grainger (J. M.) and Keddie (R. M.) (1963), - Nutritional studies on coryneform bacteria from soil and herbage. J. gen. Microbiol., 31, VIII.

GRECZ (N.), WAgENAAR (R. O.) and DACK (G. M.) (1959). - Inhibition of Clostridium botulinum by culture filtrates of Brevibacterium linens. I. Bacteriol., 78, $506 \cdot 510$

GRECZ (N.) and DACK (G. M.) (1961). - Taxonomically significant color reactions of Brevibacterium linens. J. Bacteriol., 82, 241-246.

Grecz (N.), Dack (G. M.) and Hedrick (L. R.) (1961). - Antimicrobial agent of aged surface ripened cheese. I. Isolation and assay. J. Food Sci., 26, 72-78.

GreCZ (N.), Dack (G. M.) and Hedrick (L. R.) (1962), - Antimicrobial agent of aged surface ripened cheese. II. Sources and properties of active principle(s). J. Food Sci., 27, 335-342.

Grill (H.), Patton (S.) and Cone (J.F.) (1967). - Degradation of 35S-methionine to methyl mercaptan in surface ripened cheese. J. agric. Food chem., 15, $392-393$.

Grimmer and Schmid (1936). - Mifo., 17, 286 [cité par Thomasow (J.)].

Harper (J. J.) and Davis (G. H. G.) (1979). - Two-dimensional thin-layer chromatography for amino acid analysis of bacterial cell walls. Internat. J. syst. Bacteriol., 29, 56-58.

HaRtley (C. B.) and Jezeski (J. J.) (1954). - The microflora of blue cheese slime. J. Dairy Sci., 37, 436-445.

Hemme (D.), Boulllanne (C.), Metro (F.) and Desmazeaud (M. J.) (1982). - Microbial catabolism of amino acids during cheese ripening. Sci. Aliments, 2, 113-123.

Hosono (A.) (1968 a). - Production of volatile fatty acids by Brevibacterium linens. I. Formation of volatile fatty acids from individual amino acids. Jap. J. zootechn. Sci., 39, 156-161.

Hosono (A.) (1968 b). - Production of volatile fatty acids by Brevibacterium linens. II. Formation of volatile acids from some carbohydrates and butter fat. Jap. J. zootechn. Sci., 39, 212-219.

Hosono (A.) and TOKITA (F.) (1969 a). - Studies on the production of volatile compounds by Brevibacterium linens. Jap. J. zootechn. Sci., 40, 277-283.

Hosono (A.) and TокітA (F.) (1969 b). - Studies on the decarboxylation of amino acids by Brevibacterium linens. Jap. J. zootechn. Sci., 40, 544-550. 
HRUbant (G. R.) (1973). - Characterization of the dominant aerobic microorganisms in cattle feedlot waste. Appl. Microbiol., 26, 512-516.

HugH (R.) and LEIFSON (E.) (1953). - The taxonomic significance of fermentative versus oxidative metabolism of carbohydrates by various Gram-negative bacteria. J. Bacteriol., 66, 24-26.

Iya (K. K.) and Frazier (W. C.) (1949). - The yeast in surface smear of Brick cheese. J. Dairy Sci., 32, 475-476.

JAYNe-Williams (D. J.) and Skerman (T. M.) (1966). - Comparative studies on coryneform bacteria from milk and dairy sources. $J$. appl. Bacteriol., 29, $72-92$.

JENSEn (H. L.) (1952). - The coryneform bacteria. Ann. Rev. Microbiol, 6, 77-90.

JoNES (D.), WatKINS (J.) and ERICKSON (S. K.) (1973). - Taxonomically significant colour changes in Brevibacterium linens probably associated with a carotenoid-like pigment. J. gen. Microbiol., 77, 145-150.

JoNES (D.) (1975). - A numerical taxonomic study of coryneform and related bacteria. J. gen. Microbiol., 87, 52-96.

KAYSER (E.) (1931). - Microbiologie appliquée à la transformation des produits agricoles. Ed. Baillière J. B., Paris.

Keddie (R. M.), LEASK (B. G.S.) and GRAINGER (J. M.) (1966). - A comparison of coryneform bacteria from soil and herbage: Cell wall composition and nutrition. J. appl. Bacteriol., 29, 17-43.

Keddie (R. M.) and CURE (G. L.) (1977). - The cell wall composition and distribution of free mycolic acids in named strains of coryneform bacteria and in isolates from various natural sources. J. appl. Bacteriol., 42, 229-252.

KeddiE (R. M.) and Bousfield (I. J.) (1980). - Cell wall composition in the classification of coryneform bacteria. In Goodfellow (M.), Board (R. G.) (ed.). Microbial classification and identification. Academic Press, London.

KELLY (C. D.) (1937). - The microbiological flora on the surface of Limburger cheese. J. Dairy Sci., 20, 239-246.

KELLY (C. D.) and MARQuardt (J. C.) (1939). - The influence of hydrogen ion concentration and salt on the surface flora of Limburger cheese. J. Dairy Sci., 22, 309-320.

KoHL (W.), Achenbach (H.) and Reichenbach (H.) (1983). - The pigments of Brevibacterium linens: Aromatic carotenoids. Phytochemistry, 22, 207-210.

Komagata (K.), Yamada (K.) and Ogawa (H.) (1969). - Taxonomic studies on coryneform bacteria. I. Division of bacterial cells. J. gen appl. Microbiol., $15,243-259$.

Komura (I.), Yamada (K.), Otsuka (S. I.) and Komagata (K.) (1975). - Taxonomic significance of phospholipids in coryneform and nocardioform bacteria. J. gen. appl. Microbiol., 21, 251-261.

Kraft (A. A.), Ayres (J.C.), Torrey (G.S.), Salzer (R. H.) and Silva (G. A. N.) (1966). - Coryneform bacteria in poultry, eggs and meat.J. appl. Bacteriol., $29,161-166$.

Krulwich (T. A.) and Pelliccione (N. J.) (1979). - Catabolic pathways of coryneform, nocardias, and mycobacteria. Ann. Rev. Microbiol., 33, 95-111.

Kunz (B.), HANTzschel (A.) und Singer (G.) (1980). - Submersfermentierte Brevibacterium linens -Kulturen-Beispiel für die Weiterentwicklung der mikrobiellen Verfahrenstechnik in der Lebensmittelmikrobiologie. Milchforsch-Milchpraxis, 22, 67-69.

KUNZ (B.) und SINGER (B.) (1981). - Ergebnisse vergleichender Untersuchungen emers- und submerskultivierter Brevibacterium linens-Kultur. MilchforschMilchpraxis, 23, 17-20. 
LACHANCE (R.A.) (1960). - The vitamin requirements of Corynebacterium sepedonicum (Spiek and Kott.) Skapt. and Burkh. Can. J. Microbiol., 6, $171-174$.

LACHANCE (R.A.) (1962). - The amino acid requirements of Corynebacterium sepedonicum (Spiek. and Kott.) Skapt. and Burkh. Can. J. Microbiol., 8, $321-325$.

LAW (B. A.) and SHARPE (E.) (1978). - Formation of methanethiol by bacteria isolated from raw milk and Cheddar cheese. J. Dairy Res., 45, 267-275.

LEDFORD (R. A.) and CHEN (J.H.) (1969). - Degradation of DDT and DDE by cheese microorganisms. J. Food Sci., 34, 386-388.

Lehmann (K. B.) und Neumann (R.) (1896), - Atlas und Grundriss der Bakteriologie und Lehrbuch der speciellen bakteriologischen Diagnostik. Ed. Lehmann (J. F.), München.

LelliotT (R.A.) (1966). - The plant pathogenic coryneform bacteria. J. appl. Bacteriol., 29, 114-118.

LEwIs (B. A.) (1980). - A study of the antifungal agent(s) produced by four strains of Brevibacterium linens. Diss. Abstr. Internat. B, 41, 1655-1656.

LEwIs (B. A.) (1982). - Inhibition of several food spoilage fungi by an antifungal agent(s) produced by Brevibacterium linens (Wolff) Breed. Phyton, 42, 45-48.

LEY (J. DE) (1970). - Reexamination of the association between melting point, buoyant density, and chemical base composition of deoxyribonucleic acid. J. Bacteriol., 101, 738-754.

LochHeAd (A. G.) and THEXton (R. H.) (1951). - Vitamin $B_{12}$ as a growth factor for soil bacteria. Nature, 167, 1034.

LochHeAd (A. G.) and Burton (M. O.) (1955). - Qualitative studies of soil microorganisms. XII. Characteristics of vitamin $\mathrm{B}_{12}$ requiring bacteria. Can $J$. Microbiol., 1, 319-330.

MARTH (E. H.) (1967). - Aflatoxins and other mycotoxins in agricultural products. J. Milk. Food Technol., 30, 192-198.

MEYER (R. I.) (1949). - A study of some of the B-vitamin requirements of nonsporeforming, peptonizing, rod-shaped bacteria isolated from the surface of Limburger cheese. M.S. Thesis. Univ. of Ill.

Mohan (K.) (1981). - Brevibacterium species from poultry. Antonie van Leeuwenhoek, 47, 449-453.

MoHanty (U.) (1951). - Corynebacterium fascians (Tilford) Dowson; Its morphology, physiology, nutrition and taxonomic position. Trans. br. mycol. Soc., $34,23$.

Morris (H. A.), COMBS (W. B.) and Coulter (S. T.) (1951). - The relation of surface growth to the ripening of Minnesota blue cheese. I. Dairy Sci., 34, 209-218.

Mueleer (J.H.) (1940). - Nutrition of the diphteria bacillus. Bacteriol. Rev., 4, 97-134.

Mulder (E. G.) et Antheunisse (J.) (1963). - Morphologie, physiologie et écologie des Arthrobacter. Ann. Inst. Pasteur, 105, 46-74.

Mulder (E. G.), Adamse (A. D.), Antheunisse (J.), Deinema (M. H.), Woldendorp (J. W.) and ZevenHuizen (L. P. T.M.) (1966). - The relationship between Brevibacterium linens and bacteria of the genus Arthrobacter. J. appl. Bacteriol., 29, 44-71.

Nagoya University (1978). - Wastewater treatment. U.S. Pat. 4220527.

Nobile (A.), Charney (W.), Perlman (P. L.), Herzog (H. L.), Payne (C. C.), Tully (M. E.), JeVNiK (M. A.) and Hershberg (E. B.) (1955). - Microbiological transformation of steroids. I. 1 1,4-diene-3-ketosteroids. J. Amer. Chem. Soc., 77,4184 
Ohlson (S.), LARSSON (P. O.) and Mosbach (K.) (1978). - Steroid transformation by activated living immobilized Arthrobacter simplex cells. Biotechnol. Bioeng., 20, 1267-1284.

Orlita (A.), Urbanova (E.) and Lacnakova (B.) (1978). - Pickling of pelts. CS. Pat. 172763 .

OWENS (J. D.) and KEDDIE (R. M.) (1968). - A note on the vitamin requirements of some coryneform bacteria from soil and herbage. J. appl. Bacteriol., 31, $344-348$.

OWENS (J. D.) and KEDDIE (R. M.) (1969). - The nitrogen nutrition of soil and herbage coryneform bacteria. J. appl. Bacteriol., 32, 338-347.

Parliment (T. H.), Kolor (M.G.) and Rizzo (D. J.) (1982). - Volatile components of Limburger cheese. J. Agric. Food Chem, 30, 1006-1008.

Phaff (H.) (1981). - Les micro-organismes industriels. Pour la Science, N.S., 25-39.

Pilet (C. H.), Bourdon (J. L.), Toma (B.) et Marchal (N.) (1975). - Bactériologie médicale et vétérinaire. Systématique bactérienne. Ed. Doin, Paris.

Pitcher (D. G.) and NoBle (W. C.) (1978). - Aerobic diphtheroids of human skin. In Coryneform Bacteria. Ed. Bousfield (I. J.) and Callely (A. G.), London. Academic Press.

Purko (M.), Nelson (W. O.) and Wood (W. A.) (1951 a). - The associative action between certain yeasts and Bacterium linens. J. Dairy Sci., 34, 699-705.

Purko (M.), Nelson (W. O.) and Wood (W. A.) (1951 b). - The equivalence of pantothenic acid and $\mathrm{p}$. aminobenzoic acid for growth of Bacterium linens. J. Dairy Sci., 34, 874-878.

PuRko (M.), Nelson (W. O.) and Wood (W. A.) (1953). - The nutritional equivalence of pantothenate and $\mathrm{p}$, aminobenzoate for the growth of Bacterium linens. J. Bacteriol., 66, 561-567.

Reinbold (G. W.) and REDDY (M. S.) (1974), - Sensitivity or resistance dairy starter and associated microorganisms to selected antibiotics. J. Milk Food Technol., 37, 517-521.

RICHARD (J.) et ZADI (H.) (1983), - Inventaire de la flore bactérienne dominante des Camemberts fabriqués avec du lait cru. Le Lait, 63, 25-42.

Rogosa (M.) and KEDDIE (R. M.) (1974). - Brevibacterium. In Bergey's Manual of Determinative Bacteriology. 8th ed, Ed. Buchanan (R.E.) and Gibbons (N. E.). The William and Wilkins Co, Baltimore.

Rose (A.) (1981). - La production des aliments et des boissons, Pour la Science, N.S., $120-130$.

SAN Clemente (C. L.) and Vadhera (D. V.) (1967). - Instrumental assay of microbial lipase at constant pH. Appl. Microbiol., 15, 110-113.

SANSONETTI (F.) (1930). - Sur les flores bactériennes et fongiques des caillés de lait. Rôle des symbioses dans la maturation du Camembert. Le Lait, 10, $627-640 ; 782-793 ; 858-874 ; 1109-1122$.

SCHEFFERLE (H. E.) (1966), - Coryneform bacteria in poultry deep litter, J. appl. Bacteriol., 29, 147-160.

SCHLEIFER (K. H.) and Kandler (O.) (1972), - Peptidoglycan types of bacterial cell walls and their taxonomic implications. Bacteriol. Rev., 36, 407-477.

SeILeR (H.) and Hennlich (W.) (1983). - Characterization of coryneform bacteria in piggery wastes. System. Appl. Microbiol., 4, 132-140.

Sharpe (E.), Law (B. A.), Phillips (B. A.) and Pitcher (D. G.) (1977). - Methanethiol production by coryneform bacteria: Strains from dairy and human skin sources and Brevibacteritum linens. J. gen. Microbiol., 101, 345-349. 
SHiH (C. N.) and MARTH (E. H.) (1972). - Experimental production of aflatoxin on Brick cheese. J. Milk. Food Technol., 35, 585-587.

Silva (G. A. N. DA) and Holt (J.G.) (1965). - Numerical taxonomy of certain coryneform bacteria. J. Bacteriol., 90, 921-927.

SKERMAN (T. M.) and JAYNE-Williams (D. J.) (1966). - Nutrition of coryneform bacteria from milk and dairy sources. J. appl. Bacteriol., 29, 167-178.

SKYRING (G. W.) and QUADLING (C.) (1970). - Soil bacteria: A principal component analysis and guanine-cytosine contents of some Arthrobacter-coryneform soil isolates and of some named cultures. Can. J. Microbiol., 16, 95-106.

SøRHAUG (T.) and ORDAL (Z. J.) (1974). - Cell-bound lipase and esterase of Brevibacterium linens. Appl. Microbiol., 27, 607-608.

S $\varnothing$ RHAUG (T.) (1981). - Comparison of peptide hydrolases from six strains of Brevibacterium linens. Milchwissenschaft, 36, 137-139.

Stackebrandt (E.), Lewis (B. J.) and Woese (C. R.) (1980). - The phylogenetic structure of the coryneform group of bacteria. Zbl. Bakteriol. I. Abt. Orig. C 1, 137-149.

StadHouders (J.) and LANGeveld (L. P. M.) (1962). - The microflora of the surface of cheese. Factors affecting its composition. XVII Internat. Dairy Cong., D, 577-584.

STARR (M. P.) (1949). - The nutrition of phytopathogenic bacteria. III. The Gram-positive phytopathogenic Corynebacterium species. J. Bacteriol., 57, 253-258.

Steel (K. J.) (1961). - The oxidase reaction as a taxonomic tool. J. gen. Microbiol., 25, 297-306.

Steinfatt (1930). - Mifo., 9, 1 [cité par Thomasow (J.)].

Thomasow (J.) (1950). - Uber enzyme des Bakterium linens. Kieler milchw. Forsch. Ber., 1, 35-62.

ToKita (F.), Hosono (A.), Gojo (T.) and NAKamuRa (M.) (1966). - Primary observation on the production of volatile substances by Brevibacterium linens. J. Fac. Agric. Shinshu Univ., 4, 105-120.

Tokita (F.) and Hosono (A.) (1968 a). - Studies on and behaviour of amines produced by Brevibacterium linens. Milchwissenschaft, 23, 690-693.

ToKita (F.) and Hosono (A.) (1968 b). - Production of volatile sulfur compounds by Brevibacterium linens. Jap. J. Zootechn. Sci., 39, 127-132.

TокітA (F.) and Hosono (A.) (1972). - Studies on the extracellular protease produced by Brevibacterium linens. I. Production and some properties of the extracellular protease. Jap. J. Zootechn. Sci., 43, 39-48.

Toolens (H. P.) and Koning-Theune (W.) (1970). - A selective medium for the detection of Brevibacterium linens in cheese. Milchwissenschaft, 25, 79-83.

TORgersen (H.) and SørHaUg (T.) (1978). - Peptide hydrolases of Brevibacterium linens. FEMS Microbiol. Lett., 4, 151-153.

UdAKa (S.) and SHODA (M.) (1979). - Purifying wastewaters containing phosphorus compounds using microorganisms. Ger. Pat. 2902365.

Veisseyre (R.) (1975). - Technologie du lait. 3e éd. Ed. La Maison Rustique, Paris.

Veldkamp (H.), Berg (G. Van Den) and Zevenhuizen (L. P. T. M.) (1963). -Glutamic acid production by Arthrobacter globiformis. Antonie van Leeuwenhoek, 29, 35-51.

VeldKAMP (H.) (1970). - Saprophytic coryneform bacteria. Ann. Rev. Microbiol., 24, 209-240.

WeckBach (L. S.) and Marth (E. H.) (1977). - Aflatoxin production by Aspergillus parasiticus in a competitive environment. Mycopathologia, 62, 39-49. 
Weigmann (H.) (1933). - Handbuch der praktischen Käserei. 4te Aufl. Ed. Parey (P.), Berlin.

WILKINS (P. O.) (1973). - Psychrotrophic Gram-positive bacteria: temperature effects on growth and solute uptake. Can. J. Microbiol., 19, 909-915.

WiLsoN (G. S.) and Miles (A. A.) (1964). - Topley and Wilson's principles of bacteriology and immunity. $2^{\mathrm{e}}$ vol., 5th ed. Ed. Arnold (E.), London.

WoLFF (A.) (1909). - Welche mikroorganismen beteiligen sich an der bildung des rotgelben Farbstoffes auf der Oberfläche der Käse im Reifungskeller. Milchw. Zentbl., 5, 145-414.

WolfF (A.) (1910). - Milchwirtschaftliche Bakteriologie. Centbl. Bakterio. Parasit Kde. II Abt, 28, 417-422.

Wood (B. J. F.) (1967). - Microbiology of oceans and estuaries. Ed. Elsevier publ. Co, Amsterdam.

Yamada (K.) and Komagata (K.) (1970 a). - Taxonomic studies on coryneform bacteria. II. Principal amino acid in the cell wall and their taxonomic significance. J. gen. appl. Microbiol., 16, 103-113.

Yamada (K.) and Komagata (K.) (1970 b). - Taxonomic studies on coryneform bacteria. III. DNA base composition of coryneform bacteria. J. gen. appl. Microbiol., 16, 215-224.

Yamada (K.) and Komagata (K.) (1972 a). - Taxonomic studies on coryneform bacteria. IV. Morphological, cultural, biochemical, and physiological characteristics. J. gen. appl. Microbiol., 18, 399-416.

Yamada (K.) and Komagata (K.) (1972 b). - Taxonomic studies on coryneform bacteria. V. Classification of coryneform bacteria. J. gen. appl. Microbiol., $18,417-431$.

Yamada (K.), Inouye (G.), Tahara (Y.) and Kondo (K.) (1976). - The menaquinone system in the classification of coryneform and nocardioform bacteria and related organisms. J. gen. appl. Microbiol., 22, 203-214. 